\title{
Monitoring rapid permafrost thaw using elevation models generated from satellite radar interferometry
}

\section{Other Conference Item}

Author(s):

Bernhard, Philipp; Zwieback, Simon; Leinss, Silvan (D); Hajnsek, Irena

Publication date:

2020-06-12

Permanent link:

https://doi.org/10.3929/ethz-b-000453189

Rights / license:

Creative Commons Attribution 4.0 International

Originally published in:

EGUsphere, https://doi.org/10.5194/egusphere-egu2020-6965 
EGU2020-6965, updated on 26 Nov 2020

https://doi.org/10.5194/egusphere-egu2020-6965

EGU General Assembly 2020

(c) Author(s) 2020. This work is distributed under

the Creative Commons Attribution 4.0 License.

\title{
Monitoring rapid permafrost thaw using elevation models generated from satellite radar interferometry
}

\author{
Philipp Bernhard ${ }^{1}$, Simon Zwieback ${ }^{2}$, Silvan Leinss ${ }^{1}$, and Irena Hajnsek ${ }^{1,3}$ \\ ${ }^{1}$ ETH Zürich, Institute of Environmental Engineering , Department of Civil, Environmental and Geomatic Engineering, \\ Switzerland (bernhard@ifu.baug.ethz.ch) \\ ${ }^{2}$ Geophysical Institute at the University of Alaska Fairbanks, Fairbanks AK, USA \\ ${ }^{3}$ German Aerospace Center (DLR) e.V. Microwaves and Radar Institute, Wessling, Germany
}

Vast areas of the Arctic host ice-rich permafrost, which is becoming increasingly vulnerable to terrain-altering thermokarst in a warming climate. Among the most rapid and dramatic changes are retrogressive thaw slumps. These slumps evolve by a retreat of the slump headwall during the summer months, making them detectable by comparing digital elevation models over time using the volumetric change as an indicator. Despite the availability of many topographic InSAR observations to generate digital elevation models, there is currently no method to map and analyze retrogressive thaw slumps.

Here, we present and assess a method to detect and monitor thaw slumps using time-series of elevation models (DEMs), generated from single-pass InSAR observations, which have been acquired across the Arctic at high resolution since 2011 by the TanDEM-X satellite pair. At least three observations over this timespan are available with a spatial resolution of about 12 meter and the height sensitivity of 0.5-2 meter. We first difference the generated digital elevation and detect significant elevation changes taking the uncertainty estimates of each elevation measurement into account. In the implementation of the processing chain we focused on making it as automated as much as possible to be able to cover large areas of the northern hemisphere. This includes detecting common problems with the data and apply appropriate algorithms to obtain DEMs with high accuracy. Additionally we implemented methods to deal with problematic features like wet-snow, vegetation and water bodies. After generating the DEMs we us DEM differencing followed by a blob detection and cluster algorithm to detect active thaw slumps. To improve the accuracy of our method we apply and compare different machine learning methods, namely a simple threshold method, a Random Forest and a Support-Vector-Machine. To estimate the accuracy of our method we use data from past studies as well as a classification based on optical satellite data.

The obtained locations of thaw slumps can be used as a starting point to extract important slump properties, like the headwall height and volumetric change, which are currently not available on regional scales. Additionally to the thaw slump detection, we show first results of the thaw slump property extraction for thaw slumps located in Northern Canada (Peel Plateau, Mackenzie River Delta, Banks Island, Ellesmere Island). 
